\title{
Magnitude of Preterm Birth and Its Associated Factors: A Cross-Sectional Study at Butajira Hospital, Southern Nations, Nationalities, and People's Region, Ethiopia
}

\author{
Ritbano Ahmed Abdo (D), ${ }^{1}$ Hassen Mosa Halil, ${ }^{1}$ Muhammed Abdu Muhammed, ${ }^{2}$ \\ and Mohammed Sultan Karebo ${ }^{3}$ \\ ${ }^{1}$ Department of Midwifery, College of Medicine and Health Sciences, Wachemo University, Hossana, Ethiopia \\ ${ }^{2}$ Department of Midwifery, College of Health Sciences, Samara University, Samara, Ethiopia \\ ${ }^{3}$ Department of Statistics, College of Natural and Computational Science, Wachemo University, Hosanna, Ethiopia \\ Correspondence should be addressed to Ritbano Ahmed Abdo; ritbano2244@gmail.com
}

Received 13 December 2019; Accepted 28 May 2020; Published 11 June 2020

Academic Editor: Samuel Menahem

Copyright (C) 2020 Ritbano Ahmed Abdo et al. This is an open access article distributed under the Creative Commons Attribution License, which permits unrestricted use, distribution, and reproduction in any medium, provided the original work is properly cited.

\begin{abstract}
Background. Preterm birth infants are at a greater risk of mortality and a variety of health and developmental problems; reliable data support that this rate is increasing in almost all countries. The purpose is to find the magnitude of preterm birth and its associated factors among newborns delivered at Butajira Hospital, Southern Nations, Nationalities, and People's Region, Ethiopia. Methods. This hospital-based cross-sectional study was carried out on 304 maternity cards using the systematic sampling method during May 1-21 in 2019. The data collection was performed using a structured case record form. The data were entered into EpiData software (version 3.1) and analyzed using SPSS software (version 21). Binary and multivariable logistic regression analyses were computed to identify the associated factors at 95\% CI. Results. Overall magnitude of preterm birth was observed to be $15.5 \%$. The factors significantly associated with the preterm birth were preeclampsia (AOR $=4.0 ; 95 \%$ CI: 1.6-10.0), and premature rupture of fetal membranes (AOR $=4.2 ; 95 \%$ CI: 1.4-12.9). Conclusion. Preterm birth is still public concern in the study area. The concerned administrative body should implement health education programs and improve the quality of health care delivered to pregnant mothers to control these associated factors and, consequently, promote public health in the study area.
\end{abstract}

\section{Introduction}

The World Health Organization (WHO) defines a preterm birth as birth that occurs before 37 completed weeks of gestation, or fewer than 259 days from the first date of a woman's last menstrual period [1]. Preterm infants are at a greater risk of mortality and of having a variety of health and developmental problems [2]. Fifteen million babies are born prematurely worldwide each year [3] and more than $80 \%$ of these births occur in Asia and Sub-Saharan Africa. Reliable data reveals that this rate is increasing in almost all countries [4, 5]. However, the rate can vary widely in different countries. For example, preterm births make up $13.4 \%$ of deliveries in North Africa compared to $8.7 \%$ in Europe [5].
Prematurity has become the leading cause of newborn mortality worldwide, resulting in more than one million deaths each year. Responsible for $35 \%$ of worldwide neonatal deaths, the condition is the second leading cause of death among children under five after pneumonia $[3,5]$. In Ethiopia, 320,000 babies are born early each year and 24,400 children under five die directly due to preterm complications [6]. Additionally, institution-based studies conducted in Ethiopia show a high rate of neonatal death due to preterm birth $[7,8]$. Those newborns who initially survive will face both short and long-term complications. Short-term complications include acute respiratory, gastrointestinal, immunologic, and central nervous system problems. Long-term complications of preterm birth include motor, cognitive, 
visual, hearing, behavioural, social-emotional, health, and growth problems. These issues may not become apparent until later years though may become clear and persist well into adulthood [9]. Due to this, a preterm birth could have a significant and negative financial consequence on the family of the infant $[10,11]$.

A variety of factors can contribute to preterm birth, including history of previous preterm birth [12, 13], pregnancy induced hypertension $[12,14,15]$ premature rupture of foetal membranes, $[14,16,17]$ multiple pregnancy, bleeding during pregnancy $[12,18]$, history of abortion $[14,18$, 19], foetal malformation $[14,15,20]$, inadequate antenatal care (less than four visits) follow up $[13,15,16]$, polyhydramnios $[17,18]$, previous caesarean section [14], and rural residence [19].

At present, local data is crucial to implement an intervention in order to reduce the risk of preterm birth. In Ethiopia, as observed in different studies from across the country, the prevalence of preterm birth is estimated to be between as low as $4.4 \%$ [19] and as high as $25.9 \%$ [16]. The geographical distribution and other factors associated with preterm birth vary across different cultures and socioeconomic statuses within a society. Therefore, the results gained from a study of one area might not be relevant to other areas $[14,19,21,22]$. With this in mind, this study has endeavoured to find the magnitude of preterm birth and its associated factors of preterm birth among newborns delivered at Butajira Hospital, Southern Nations, Nationalities, and People's Region, Ethiopia.

\section{Methods and Materials}

2.1. Study Design, Setting, Period, and Population. A hospitalbased cross-sectional study was carried out in Butajira Hospital from May 1 to 21, 2019. The study populations for the study were randomly chosen maternity cards for mothers who had given birth at the Butajira Hospital in the previous year prior to the data collection period.

2.2. Sampling Size and Sampling Procedure. The sample size of 304 was calculated using a single population proportion formula with the following assumptions; the proportion of preterm birth was taken from the study conducted in Jimma University Specialized Teaching and Referral Hospital of $25.9 \%$ [16], with a $95 \%$ confidence interval, margin of error of $5 \%$, and $10 \%$ missed-items. A systematic random sampling technique was used to select the study subjects (cards).

2.3. Data Collection Tool, Procedure and Quality Control. A pretested case record form was used to review data from maternal cards, which was adapted from other related researches [13-23]. Midwives, two with diplomas and one with a bachelor's degree, were hired for the data collection and supervision. The quality of data was maintained through; a data collection form was pretested on $5 \%$ of a calculated sample size before the actual data collection period in the Workable Comprehensive Hospital. The data collectors were given a one-day intensive instruction on the study tool and data collection. Additionally, the data collectors worked under the close observation of the supervisors to ensure reliability in correct data collection procedures. Moreover, all filled forms were checked daily for completeness, accuracy, clarity, and consistency by the supervisors and the principal investigators. Completeness and consistency of variables during data entry and analysis were checked using frequency distributions.

2.4. Data Management and Analysis. The collected data were coded and entered using EpiData version 3.1 software to minimize errors and design skipping patterns. Then, the data were exported and analyzed using SPSS version 24.0. Descriptive statistics, frequency, and proportions were computed to summarise the data. Bivariate analysis between outcome and independent variables was performed separately using binary logistic regression. The strength and direction of the association between an outcome variable and independent variables were expressed in odds ratio through 95\% CI. To identify independent factors, the first bivariate logistic regression analyses were carried out to select a candidate for multivariable logistic regression analyses. Multivariable logistic regression analyses were done for variables that have $p$ value $\leq .25$ during the bivariate logistic regression analyses to identify factors associated with the outcome variable and to control for potential confounders. Association between independent and dependent variables were assessed using odds ratio with $95 \%$ confidence interval. At the end, $p<$ 0.05 was considered as statistically significant in the multivariable model. Hosmer-Lemeshow goodness-of-fit statistic was used to check the necessary assumptions for multivariable logistic regressions was fulfilled.

2.5. Operational Definition. Gestational age was estimated based on her last normal menstrual period, using an ultrasound report from chart review.

2.6. Ethical Consideration. This study was approved by Wachemo University, research and community services directorate office. Additionally, permission was obtained from the hospital authority before commencing the data collection.

\section{Result}

3.1. Socio-Demographic, Obstetric, Medical, and Fetal Characteristics. A total of 304 maternity cards were reviewed in this study, wherein the response rate was $100 \%$. Two hundred forty-two (79.6\%) of mothers were aged between 20 and 34 years. The majority of them, 300 (98.7\%) were married, while 208 (68.4\%) were urban residents. Regarding parity, 193 (63.5\%) mothers were multigravida, and the other $28.6 \%$ were primipara. Thirty $(9.9 \%)$ mothers had ever experienced abortion. More than half of the mothers 161 (53\%) had four or more antenatal care visits. During their last pregnancy, 28 (9.2\%), 10 (3.3\%), and 17 (5.6\%) of mothers faced the preeclampsia, antepartum haemorrhage, and premature rupture of fetal membranes, respectively.

The majority of the mothers delivered 293 (96.4\%) alive neonates. Of these, 27 (9.2\%) were low birth weight. 
According to reports in the mothers' cards, 7 (2.3\%) mothers were HIV positive, and in $27(8.6 \%)$ of the mothers, the hemoglobin level was less than $11 \mathrm{gm} / \mathrm{dl}$ (Table 1$)$.

3.2. The Magnitude of Preterm Birth. In this study, the overall magnitude of preterm birth was observed to be 47 (15.5\%) (Figure 1).

3.3. Associated Factors of Preterm Birth. The outcome of bivariate logistic regression analysis showed that mothers aged $\geq 35$ years, being rural residents, with history of previous preterm birth, grand multiparty, and less than 4 antenatal care visits were associated factors for preterm birth. However, in multivariable logistic regression, preeclampsia and premature rupture of fetal membranes were found to be significantly associated with preterm birth. Preterm birth was four times more likely to occur in mothers with preeclampsia in comparison to their counterparts $(\mathrm{AOR}=5.1 ; 95 \% \mathrm{CI}: 2.0$, 13.3). Also, mothers with premature rupture of fetal membranes were four or more times more likely to have a preterm birth than their counterparts ( $\mathrm{AOR}=4.2,95 \% \mathrm{CI}: 1.4,12.9$ ) (Table 2).

\section{Discussion}

In this study, the prevalence of preterm birth was observed to be $15.5 \%$ and is higher than those of other studies conducted in Brazil, India, Gondar (Ethiopia), and Iran, which were $11.5 \%, 5.8 \%, 4.4 \%$, and $5.1 \%$, respectively $[17,20,21,23]$. This high rate may be due to the fact that the rate of preterm birth is increasing worldwide [3] and that mothers in the abovementioned countries may have better preterm birth prevention rates. In contrast, this study found a lower prevalence of preterm birth compared to other studies in Jimma (Ethiopia) and Kenya, which were $25.9 \%$ and $18.3 \%$, respectively $[16,22]$. This variation may be due to difference in the study design, study setting, sociocultural status, and implementation of the health-related program. In addition, the prevalence of preterm birth may vary between and within geographical regions [4].

The observed association between preeclampsia during pregnancy with preterm birth is consistent with studies conducted in Iran [12], India [14, 17], Ethiopia [15, 16, 19], and Peru [13]. The reason for this may be mothers with preeclampsia have a greater risk of undergoing preterm birth, as definite intervention of severe preeclampsia terminates pregnancy, thus resulting in preterm.

The finding of this study also revealed that mothers with the premature rupture of fetal membranes were associated with preterm birth. This is comparable with studies done in Iran [12], India [14, 21], and Ethiopia $[16,19]$. The reason of these might be due to the fact that labor starts within 24 hours after premature rupture of fetal membranes so increases of preterm labor and preterm birth.

This study understandably shares the limitations of cross-sectional studies. First, as a cross-sectional study, the associations observed between the independent variables
TABle 1: Socio-demographic, obstetric, medical, and fetal characteristics in the Butajira Hospital, 2019.

\begin{tabular}{|c|c|c|c|}
\hline Variables & & $\begin{array}{l}\text { Frequency } \\
(N=304)\end{array}$ & Percent \\
\hline \multirow{3}{*}{ Age group } & $<20$ & 32 & 10.5 \\
\hline & $20-34$ & 242 & 79.6 \\
\hline & $\geq 35$ and above & 30 & 9.9 \\
\hline \multirow{2}{*}{ Residency } & Urban & 208 & 68.4 \\
\hline & Rural & 96 & 31.6 \\
\hline \multirow{2}{*}{ Marital status } & Married & 300 & 98.7 \\
\hline & Single & 4 & 1.3 \\
\hline \multirow{3}{*}{ Gravidity } & Primipara & 87 & 28.6 \\
\hline & Multipara & 193 & 63.5 \\
\hline & Grand multipara & 24 & 7.9 \\
\hline \multirow{2}{*}{ Ever had abortion } & No & 274 & 90.1 \\
\hline & Yes & 30 & 9.9 \\
\hline \multirow{2}{*}{$\begin{array}{l}\text { History of previous } \\
\text { preterm birth }\end{array}$} & No & 253 & 83.2 \\
\hline & Yes & 51 & 16.8 \\
\hline \multirow{2}{*}{ ANC follow-up } & Four or above visits & 161 & 53.0 \\
\hline & Less than four visit & 143 & 47.0 \\
\hline \multirow{2}{*}{ Preeclampsia } & No & 276 & 90.8 \\
\hline & Yes & 28 & 9.2 \\
\hline \multirow{2}{*}{$\begin{array}{l}\text { Prerupture of fetal } \\
\text { membranes }\end{array}$} & No & 287 & 94.4 \\
\hline & Yes & 17 & 5.6 \\
\hline \multirow{2}{*}{$\begin{array}{l}\text { Antepartum } \\
\text { hemorrhage }\end{array}$} & No & 294 & 96.7 \\
\hline & Yes & 10 & 3.3 \\
\hline \multirow{2}{*}{ Onset of labor } & Spontaneous & 296 & 97.4 \\
\hline & Induction & 8 & 2.6 \\
\hline \multirow{3}{*}{ Mode of delivery } & $\begin{array}{l}\text { Normal vaginal } \\
\text { delivery }\end{array}$ & 242 & 79.6 \\
\hline & Operative vaginal & 28 & 9.2 \\
\hline & Caesarean delivery & 34 & 11.2 \\
\hline \multirow{2}{*}{ Delivery status } & Single & 280 & 92.1 \\
\hline & Multiple & 24 & 7.9 \\
\hline \multirow{2}{*}{ Preterm birth } & No & 257 & 84.5 \\
\hline & Yes & 47 & 15.5 \\
\hline \multirow{2}{*}{ Sex of fetus } & Female & 135 & 44.4 \\
\hline & Male & 169 & 55.6 \\
\hline \multirow{2}{*}{ Fetal status } & Alive & 293 & 96.4 \\
\hline & Still birth & 11 & 3.6 \\
\hline \multirow{2}{*}{$\begin{array}{l}\text { Birth weight of live } \\
\text { birth baby }(N=293)\end{array}$} & $\begin{array}{c}\text { Normal birth weight } \\
\quad(2.5-4 \mathrm{~kg})\end{array}$ & 266 & 91.8 \\
\hline & $\begin{array}{l}\text { Low birth weight } \\
\quad(<2.5 \mathrm{~kg})\end{array}$ & 27 & 9.2 \\
\hline \multirow{2}{*}{ HIV status } & Negative & 297 & 97.7 \\
\hline & Positive & 7 & 2.3 \\
\hline \multirow{2}{*}{$\begin{array}{l}\text { Hemoglobin level } \\
\text { (prepartum) }\end{array}$} & $\geq 11 \mathrm{~g} / \mathrm{dl}$ & 277 & 91.1 \\
\hline & $<11 \mathrm{~g} / \mathrm{dl}$ & 27 & 8.9 \\
\hline
\end{tabular}




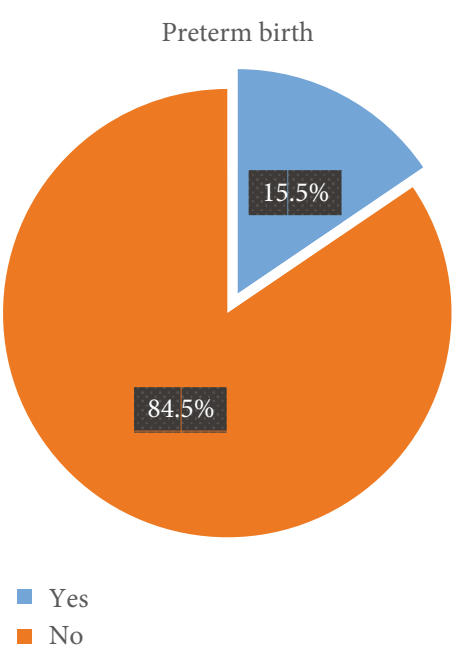

Figure 1: Magnitude of preterm birth in the Butajira Hospital, 2019.

TABle 2: Associated factors of preterm birth in the Butajira Hospital, 2019.

\begin{tabular}{|c|c|c|c|c|}
\hline \multirow[t]{2}{*}{ Variables } & \multicolumn{2}{|c|}{$\begin{array}{l}\text { Preterm } \\
\text { birth }\end{array}$} & \multirow[t]{2}{*}{$\begin{array}{l}\text { Crude odds ratio } \\
\qquad(95 \% \mathrm{CI})\end{array}$} & \multirow[t]{2}{*}{$\begin{array}{c}\text { Adjusted odds ratio } \\
(95 \% \mathrm{CI})\end{array}$} \\
\hline & & Yes & & \\
\hline \multicolumn{5}{|l|}{ Residence } \\
\hline Urban & 186 & 22 & Reference & Reference \\
\hline Rural & 71 & 25 & $3(1.6,5.6) *$ & $1.9(.8,4.3)$ \\
\hline \multicolumn{5}{|l|}{ Age group } \\
\hline$<20$ & 29 & 3 & $.7(.2,2.4)$ & $1.1(.3,4.6)$ \\
\hline $20-34$ & 211 & 31 & 1 & 1 \\
\hline$\geq 35$ & 17 & 13 & $5.2(2.3,11.8) *$ & $2.2(.7,6.8)$ \\
\hline \multicolumn{5}{|l|}{ Parity } \\
\hline Primipara & 77 & 10 & $.8(.4,1.7)$ & $1.1(.4,2.8)$ \\
\hline Multipara & 166 & 27 & Reference & Reference \\
\hline Grand multipara & 14 & 10 & $4.4(1.1,10.8) *$ & $1.5(.4,5.1)$ \\
\hline \multicolumn{5}{|l|}{ Preeclampsia } \\
\hline No & 239 & 37 & Reference & Reference \\
\hline Yes & 18 & 10 & $3.6(1.5,8.4)^{*}$ & $4.0(1.6,10.0)^{* *}$ \\
\hline \multicolumn{5}{|l|}{$\begin{array}{l}\text { ANC visit in current } \\
\text { pregnancy }\end{array}$} \\
\hline$\geq 4$ visits & 143 & 18 & Reference & Reference \\
\hline$<4$ visits & 114 & 29 & $2.0(1.1,3.8) *$ & $1.0(.4,2.1)$ \\
\hline \multicolumn{5}{|l|}{$\begin{array}{l}\text { Premature rupture } \\
\text { of fetal membranes }\end{array}$} \\
\hline No & 248 & 39 & Reference & Reference \\
\hline Yes & 9 & 8 & $5.6(2.1,15.5) *$ & $4.2(1.4,12.9)^{* *}$ \\
\hline \multicolumn{5}{|c|}{ History premature birth } \\
\hline No & 222 & 31 & 1 & 1 \\
\hline Yes & 35 & 16 & $3.3(1.6,6.6) *$ & $2.2(.9,5.0)$ \\
\hline
\end{tabular}

and the dependent does not show causal-effect relationship. Secondly, this is a hospital-based cross-sectional study whose findings are not generalized to a general population. Finally, it is important to mention here that data was collected from each mother's card; due to this, some important variables were missing, such as previously highlighted factors with preterm birth in different studies.

\section{Conclusion}

In conclusion, preterm birth is still a public concern in the study area. Preeclampsia and premature rupture of fetal membranes were significantly associated with preterm birth. Therefore, the concerned administrative body should implement health education programs and improve the quality of health care delivered to pregnant mothers to control these risk factors and, consequently, promote public health in the study area.

\section{Data Availability}

The datasets used and analyzed during the current study are available from the corresponding author on reasonable request.

\section{Conflicts of Interest}

The authors declare that they have no competing interests.

\section{Authors' Contributions}

RA and HM conceived and designed the study. RA analyzed the data and wrote the paper. RA and HM participated in the data collection.

\section{Acknowledgments}

We are very grateful to the Wachemo University for the approval of the Ethical Clearance. We also express our heartfelt thanks to the Butajira General Hospital authorities, supervisors, and data collectors.

\section{References}

[1] D. Dc, Textbook of Obstetrics. Including Perinatology and Contraception, Jaypee Brothers Medical Publishers, New Delhi, 7 edition, 2013.

[2] Institute of Medicine, Preterm Birth: Causes, Consequences, and Prevention, R. E. Behrman and A. S. Butler, Eds., The National Academies Press, Washington DC, USA, 2007.

[3] WHO, UNICEF, World Bank, and UN-DESE, Population division, Levels and Trends in Child Mortality, 2015.

[4] S. Chawanpaiboon, J. P. Vogel, A.-B. Moller et al., "Global, regional, and national estimates of levels of preterm birth in 2014: a systematic review and modelling analysis," The Lancet Global Health, vol. 7, pp. e37-e46, 2019.

[5] C. P. Howson, M. V. Kinney, and J. E. Lawn, Born Too Soon. The global action report on preterm birth, WHO, Geneva, Switzerland, 2012. 
[6] USAID and PCI, Profile of Preterm and Low Birth Weight Prevention and CareAvailable on: http://www.everypreemie. org.

[7] A. Deribew, G. A. Tessema, K. Deribe et al., "Trends, causes, and risk factors of mortality among children under 5 in Ethiopia, 1990-2013: findings from the Global Burden of Disease Study 2013," Population Health Metrics, vol. 14, no. 1, 2016.

[8] H. G. Mengesha and B. W. Sahle, "Cause of neonatal deaths in Northern Ethiopia: a prospective cohort study," BMC Public Health, vol. 17, no. 1, p. 62, 2017.

[9] N. Al Riyami, I. Al-Ruheili, F. Al-Shezawi, and M. Al-Khabori, "Extreme preterm premature rupture of membranes: risk factors and feto maternal outcomes," Oman Medical Journal, vol. 28, no. 2, pp. 108-111, 2013.

[10] J. A. Martin, B. E. Hamilton, P. D. Sutton et al., "Births: final data for 2007," National Vital Statistics Reports, vol. 58, no. 24, pp. 1-85, 2013.

[11] J. M. Hodek, J. M. von der Schulenburg, and T. Mittendorf, "Measuring economic consequences of preterm birth- methodological recommendations for the evaluation of personal burden on children and their caregivers," Health Economics Review, vol. 1, no. 1, p. 6, 2011.

[12] N. Tehranian, M. Ranjbar, and F. Shobeiri, "The prevalence rate and risk factors for preterm delivery in Tehran, Iran," Journal of Midwifery and Reproductive Health, vol. 4, no. 2, pp. 600-604, 2016.

[13] M. E. Ahumada-Barrios and G. F. Alvarado, "Risk factors for premature birth in a hospital," Revista latino-americana de enfermagem, vol. 24, 2016.

[14] A. Mahajan and S. Magon, "Study of risk factors for preterm births in a teaching hospital: a prospective study," International Journal of Medical and Dental Sciences, vol. 6, no. 1, p. 1407, 2017.

[15] G. Teklay, T. Teshale, H. Tasew, T. Mariye, H. Berihu, and T. Zeru, "Risk factors of preterm birth among mothers who gave birth in public hospitals of central zone, Tigray, Ethiopia: unmatched case-control study 2017/2018," BMC Research Notes, vol. 11, no. 1, p. 571, 2018.

[16] I. Bekele, T. Demeke, and K. Dugna, "Prevalence of Preterm Birth and its Associated Factors among Mothers Delivered in Jimma University Specialized Teaching and Referral Hospital, Jimma Zone, Oromia Regional State, South West Ethiopia," Journal of Women's Health Care, vol. 6, p. 356, 2017.

[17] C. R. Rao, L. E. de Ruiter, P. Bhat, V. Kamath, A. Kamath, and V. Bhat, "Case-Control Study on Risk Factors for Preterm Deliveries in a Secondary Care Hospital, Southern India," ISRN Obstetrics and Gynecology, vol. 10, 2014.

[18] R. Passini, J. G. Cecatti, G. J. Lajos et al., "Brazilian multicentre study on preterm birth (EMIP): prevalence and factors associated with spontaneous preterm birth," PLoS One, vol. 9, no. 10, p. e109069, 2014.

[19] M. Abaraya, S. Seid, and S. Ibro, "Determinants of preterm birth at Jimma university medical center, Southwest Ethiopia," Pediatric Health, Medicine and Therapeutics, vol. Volume 9, pp. 101-107, 2018.

[20] M. do Carmo Leal, A. P. Esteves-Pereira, M. NakamuraPereira et al., "Prevalence and risk factors related to preterm birth in Brazil," Reproductive Health, vol. 13, Supplement 3, p. 127, 2016.
[21] K. Gebreslasie, "Preterm Birth and Associated Factors among Mothers Who Gave Birth in Gondar Town Health Institutions," Advances in Nursing, vol. 2016, Article ID 4703138, 5 pages, 2016.

[22] P. Wagura, A. Wasunna, A. Laving, D. Wamalwa, and P. Ng'ang'a, "Prevalence and factors associated with preterm birth at Kenyatta national hospital," BMC Pregnancy and Childbirth, vol. 18, no. 1, p. 107, 2018.

[23] R. Alijahan, S. Hazrati, M. Mirzarahimi, F. Pourfarzi, and P. A. Hadi, "Prevalence and risk factors associated with preterm birth in Ardabil, Iran," Iranian Journal of Reproductive Medicine, vol. 12, no. 1, pp. 47-56, 2014. 